\title{
Measuring employment in the agri-food system: Existing data and directions for future research
}

Kate Ambler, Sylvan Herskowitz, Ricardo Labarta, Mywish Maredia, and Phoebe Scollard

Rapidly growing populations in sub-Saharan Africa have resulted in a focus by both policy-makers and researchers on understanding and creating employment opportunities for youth. While most attention has focused on jobs outside the agricultural sector, the persistent importance of agriculture in African economies means that the sector cannot be ignored when considering new employment opportunities. A large portion of existing work has made use of Living Standard Measurement Surveys (LSMS) and others of similar structure and design to describe employment patterns, by focusing on the distinction between on- and off-farm labor, and household enterprises versus hired or wage labor.

Recent work has suggested that changing tastes and diets towards more highly processed foods are driving an expansion of the agri-food industry which, in turn, is leading to the development of new, more modern value chains (Tschirley 2015; World Bank 2017). As such, this evolving sector may hold great promise for expanding employment opportunities, both on and off farm. We broaden the definition of agriculture-linked work to consider all work along agricultural value chains and in the food system, from production to consumption. Using this definition can offer a more complete view of how agriculture can drive modern employment. However, in documenting these activities, the data underlying much of this literature rarely allow for differentiation between jobs with high-value activities and those consisting of more traditional, less productive agricultural work. Additionally, most existing analysis of off-farm employment patterns has not focused on differentiating work in the agri-food system from other types of off-farm work, limiting our understanding of how this industry is shaping employment opportunities. ${ }^{1}$ In this note, we describe our effort to understand these distinctions more deeply using existing data, acknowledge gaps in the data, and suggest some directions for improved data collection.

\footnotetext{
${ }^{1}$ See examples in Mueller and Thurlow (2019).
} 
Following the existing literature, we make use of the publicly available LSMS surveys which, from our review, represent the most comprehensive, nationally representative data available on employment. We reviewed the survey instruments for a large sample of African countries and selected data from Ghana, Uganda, Tanzania, and Niger. ${ }^{2}$ These surveys were chosen because they were designed to collect occupation and industry information from all respondents (not only those engaged in wage labor as in many surveys we reviewed), with a sufficient level of detail captured in these responses for our purposes, and asked an additional question categorizing work as being done for hire/as an employee as opposed to for oneself or ones family.

We use these responses for each household member's primary activity in order to classify their employment into one of nine categories.

1. Agriculture: On-farm household/self-employed

2. Agriculture: On-farm non-household/employee

3. Agriculture: Off-farm household/self-employed

4. Agriculture: Off-farm non-household/employee

5. Maybe agriculture: Household/self-employed

6. Maybe agriculture: Non-household/employee

7. Non-agriculture: Household business/household labor/self-employed

8. Non-agriculture: Wage work/employee

9. Can't categorize

These categories allow us to draw a distinction between those who are involved in the agri-food system (categories 1-4) and those that are definitely not (categories 7-8). The recent policy focus surrounding "high-value" employment in the agri-food system has assumed that these opportunities are concentrated in off-farm agricultural work (captured in categories 3-4). The "maybe agriculture" categories represent cases where the data available in the survey did not allow us to classify the respondent into agricultural or non-agricultural work. This includes, for example, cases of sales or transport where the goods being sold or transported are not indicated and additionally, along with the agriculture categories, constitutes an upper bound of agri-food system linked employment as it stands across our sample.

The figure below shows the distribution of employment across a consolidated set of these main categories, specifically it combines non-household agriculture (categories 2 and 4), the two "maybe" agriculture groups (categories 5 and 6), and the non-agriculture categories (categories 7 and 8 ) into single categories, while omitting activities that could not be categorized (less than $1 \%$ of our sample).

Participation levels are calculated using data from 88,628 labor force participants aged 15 to 60 from the four countries. ${ }^{3}$ The graph reflects individuals' primary activity in the last seven days by gender and location (i.e., rural vs. urban). In rural areas, household's on-farm agricultural work is by far the most

\footnotetext{
${ }^{2}$ In practice, the Ghanaian survey is not an LSMS survey, but was instead conducted by the Ghana Statistical Service. However, their methodology, with respect to national representativeness and complete household listings, and labor modules, using detailed industry and occupation codes, mirror those of conventional LSMS surveys.

${ }^{3}$ Survey weights are used to adjust for differences in sample size and country populations so that figures are jointly representative of the four countries.
} 
important activity for both men and women. We note a number of differences between men and women whereby women are disproportionately involved in agricultural-related off-farm household activities, while men are more likely to be working in the non-agricultural sector. Work in off-farm, non-household, agricultural-related activities is low for both men and women, suggesting that wage work in the agrifood system remains a very small component of overall employment in rural areas. In the urban population, as expected, on-farm work is much lower, although relative patterns are similar. Men are more likely to be involved in non-agriculture work, while women are engaged in agricultural-related offfarm household activities at high levels. There is also a significant component of the population classified as maybe working in agriculture, with this incidence considerably higher for women than for men.

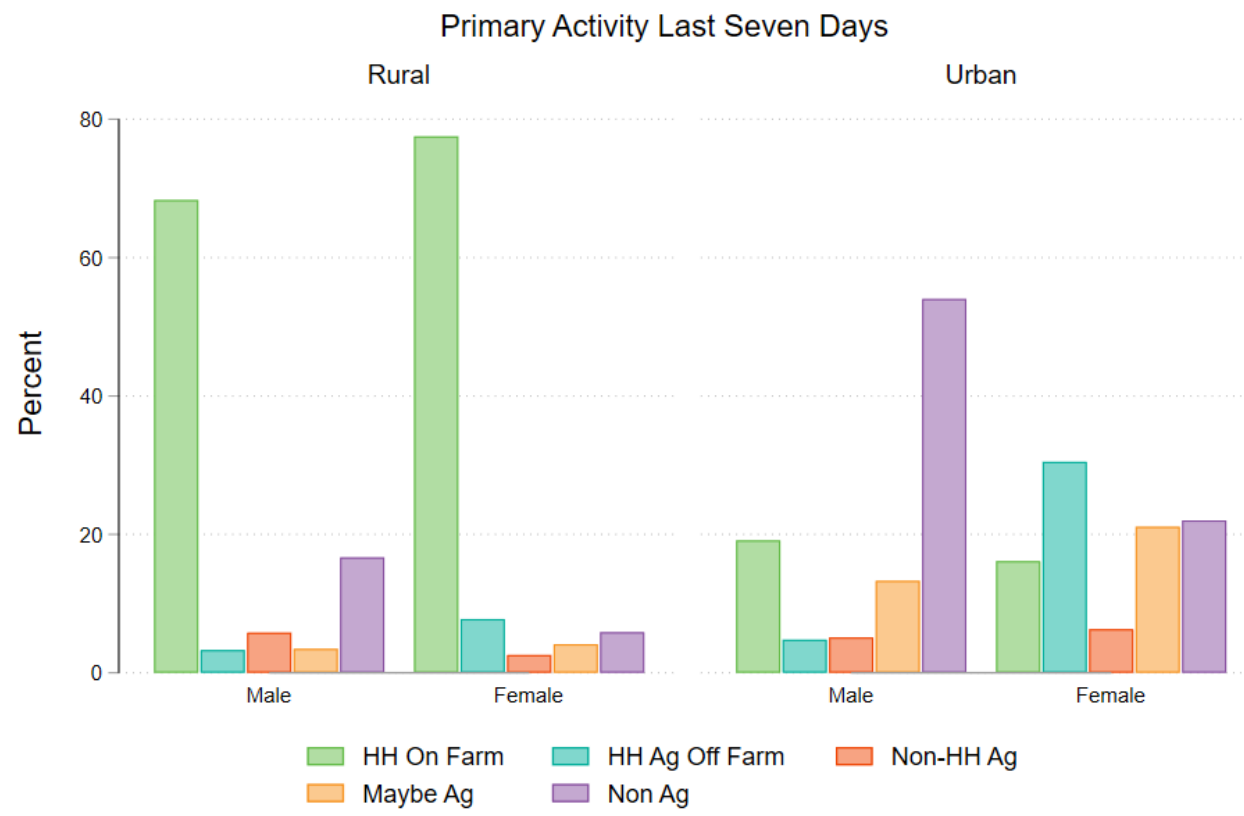

While informative, this figure also helps to highlight what we don't know. First, we cannot fully categorize employment in the agri-food system because some occupation and industry codes do not specify the product involved in an activity (such as people who are vendors or in transport, but what they sell or transport is not recorded). Second, though our classifications improve on the level of detail relative to most existing work, we are still limited in our ability to say if activities represent quality or high value employment. For example, much of the off-farm agricultural work is concentrated among women in household businesses. Further analysis of the data reveals that much of this employment may be related to direct food sales and preperation, and is unlikely to be a high-value activity. Likewise, we do not know the extent to which on-farm activities represent meaningful enagement with the agri-food system such as value-added post-harvest processing.

Finally, this figure only descibes individuals' primary activity in the last seven days. Though LSMS surveys typically also ask for secondary activities and, in some cases, primary and secondary activities in the last year, the patterns do not change substantially when taking that data into account. A limitation of the surveys that record primary and secondary activities in the last seven days or primary activity in the last 12 months is that these designations may not capture seasonal employment. It is likely that much employment in agriculture related value chains may be seasonal or otherwise temporary, and 
thus may be undermeasured if it occurs outside of the last seven days and/or is not considered to be a respondent's primary activity over the longer recall period.

The next step in our research agenda is to apply these lessons to the design of labor modules in household surveys. Specifically, we have begun testing a variety of new modules that will allow for the specific designation of whether or not activities are related to food and agriculture, and additionally for an enumeration of specific activities that compose high-value, on-farm work. We are also conducting an experiment with different methods of listing activities, such that respondents are prompted to more carefully provide a complete listing of employment activities. And finally, we are planning a series of surveys over the course of a year to test whether longer recall periods induce distortions of employment measurement and, in particular, lead to underestimates of participation in high value but seasonal activities in the agri-food system.

\section{ABOUT THE AUTHORS}

Kate Ambler is a Research Fellow, Sylvan Herskowitz is an Associate Research Fellow, and Phoebe Scollard is a Research Analyst - all with the Markets, Trade and Institutions Division (MTID) at IFPRI.

Ricardo Labarta is a Senior Scientist at CIAT.

Mywish Maredia is a Professor in the Department of Agricultural, Food, and Resource Economics at MSU.

\section{REFERENCES}

Mueller, Valerie; and Thurlow, James (Eds.). 2019. Youth and jobs in rural Africa: Beyond stylized facts. New York, NY: International Food Policy Research Institute (IFPRI) and Oxford University Press. https://doi.org/10.1093/oso/9780198848059.003.0001

Tschirley, David, Thomas Reardon, Michael Dolislager, and Jason Snyder. 2015. "The Rise of a Middle Class in east and Southern Africa: Implications for Food System Transformation.” Journal of International Development. 27: 628-646.

World Bank. 2017. "Future of Food: Shaping the Food System to Deliver Jobs."

Funding for this work was provided by the CGIAR Research Program on Policies, Institutions, and Markets (PIM). This publication has not been independently peer reviewed. Any opinions expressed here belong to the author(s) and are not necessarily representative of or endorsed by IFPRI. 